\title{
Diagnostic Validity of Serum Cystatin C for Detection of Acute Kidney Injury in Children
}

\author{
Sharmin Akter Luna ${ }^{1}$, Jakia Sultana ${ }^{2}$, Md. Abdullah Yusuf ${ }^{3}$, Golam Muin Uddin ${ }^{4}$, Md. Habibur \\ Rahman $^{5}$, Ranjit Ranjan Roy ${ }^{6}$
}

${ }^{1}$ Post-Graduate on Paediatric Nephrology, Department of Paediatric Nephrology, Bangabandhu Sheikh Mujib Medical University, Dhaka, Bangladesh; ${ }^{2}$ Registrar, Department of Paediatrics, Shaheed Ziaur Rahman Medical College, Bogura, Bangladesh; ${ }^{3}$ Associate Professor, Department of Microbiology, National Institute of Neurosciences \& Hospital, Dhaka, Bangladesh; ${ }^{4}$ Professor \& Former Chairman, Department of Paediatric Nephrology, Bangabandhu Sheikh Mujib Medical University, Dhaka, Bangladesh; ${ }^{5}$ Professor \& Former Chairman, Department of Paediatric Nephrology, Bangabandhu Sheikh Mujib Medical University, Dhaka, Bangladesh; ${ }^{6}$ Professor \& Chairman, Department of Paediatric Nephrology, Bangabandhu Sheikh Mujib Medical University, Dhaka, Bangladesh

[Received: 12 October 2020; Accepted: 30 November 2020; Published: 1 December 2020]

\begin{abstract}
Background: Detection of acute kidney injury is very essential among the children. Objective: The purpose of the present study was to validate the serum cystatin $\mathrm{C}$ for the detection of acute kidney injury in children. Methodology: This cross-sectional study was conducted in the Department of Paediatric Nephrology with the collaboration of Paediatric Gastroenterology, Paediatric Neurology, Paediatric Neonatology and Microbiology and Immunology at Bangabandhu Sheikh Mujib University, Dhaka, Bangladesh from May 2018 to July 2019 for a period of one year. Patients with the age group of 1 month to 17 years, who were at risk of AKI, and admitted in the inpatient department of Pediatrics and allied at Bangabandhu Sheikh Mujib University, Dhaka, Bangladesh during this study period in both sexes were selected as study population. To detect AKI, serum creatinine was measured at $0 \mathrm{~h}$ (baseline), $48 \mathrm{~h}$ and $5^{\text {th }}$ day respectively. Serum cystatin $\mathrm{C}$ were measured at 0 (baseline) and $48 \mathrm{~h}$ respectively for all patients. Result: A total number of 52 patients were enrolled in this study. Here the AUC was 0.93 with $95 \%$ CI $(0.864-0.995)$. Serum cystatin C had sensitivity of $95 \%$ (95\% CI 77.9\%-099.7\%) with specificity 84\% (95\% CI 73.7\%-87.3\%), PPV 79\% (95\% CI 64.9\%-83.1\%), NPV 96\% (95\% CI 84.2\%-99.8\%), accuracy $88.7 \%$ (95\% CI 75.3\%-92.1\%), positive likelihood ratio 6.08 and negative likelihood ratio 0.06 (95\% CI 2.96-7.87 and 0.003-0.300 respectively). Conclusion: In conclusion the diagnostic validity of serum cystatin $\mathrm{C}$ for the detection of AKI is very high among the children. [Bangladesh Journal of Infectious Diseases, December 2020;7(2):44-48]

Keywords: Diagnostic validity; serum cystatin C; acute kidney injury; children

Correspondence: Dr. Sharmin Akter Luna, Post-Graduate on Paediatric Nephrology, Department of Paediatric Nephrology, Bangabandhu Sheikh Mujib Medical University, Shahbag, Dhaka, Bangladesh; Email: sharminluna82@yahoo.com; Cell no.: $+8801616600646$

Conflict of interest: Authors declare that there is no conflict of interests.

Funding agency: The study was not funded by any authority.

Contribution to authors: Luna SA, Sultana J, Uddin GM, Rahman MH, Roy RR involved in protocol preparation, data collection and literature search up to manuscript writing. Yusuf MA, Rahman MH, Roy RR involved in literature search, preparation and revision of this manuscript.

How to cite this article: Luna SA, Sultana J, Yusuf MA, Uddin GM, Rahman MH, Roy RR. Diagnostic Validity of Serum Cystatin C for Detection of Acute Kidney Injury in Children. Bangladesh J Infect Dis 2020;7(2):44-48

Copyright: $\odot 2020$. Luna et al. Published by Bangladesh Journal of Infectious Diseases. This article is published under the Creative Commons CC BY-NC License (https://creativecommons.org/licenses/by-nc/4.0/). This license permits use, distribution and reproduction in any medium, provided the original work is properly cited, and is not used for commercial purposes.
\end{abstract}




\section{Introduction}

Acute kidney injury is a major public health priority worldwide. The ideal endogenous marker should have criteria of stable production rate, stable circulating levels unaffected by pathological changes, lack of protein binding, free glomerular filtration, and lack of reabsorption or secretion ${ }^{1}$. Cystatin $\mathrm{C}$ is a promising endogenous marker for all age group, which met most of these criteria ${ }^{2}$. In comparison to creatinine, it is a large molecular weight basic protein, generated by all nucleated cells of body at a relatively constant rate, and is freely filtered by the glomerulus. Unlike creatinine, it is not secreted by renal tubules rather than completely reabsorbed with subsequent degradation by proximal tubular cells ${ }^{3}$. Though it's serum concentration is influenced by some extra-renal conditions, like thyroid dysfunction, malignancy ${ }^{4}$, it does not have many influencing factors like creatinine. So, there is no matter of under or overestimation of GFR by using this marker. Cystatin $\mathrm{C}$ increases abnormally in serum when GFR decreases to $88 \mathrm{ml} / \mathrm{min} / 1.73 \mathrm{~m}^{2}$ and can detect AKI 1 to 2 days prior to serum creatinine $^{5}$. Up to date several studies suggested that cystatin $\mathrm{C}$ is a preferred and sensitive marker for early detection of acute kidney injury ${ }^{6-8}$.

Early diagnosis is very important for early intervention. Serum creatinine concentration measurement is the most common and conventional method for detecting AKI, which often fails to identify those patients with moderately reduced renal function ${ }^{9}$. Using this marker detection of renal failure cannot be obtained until GFR decreased by more than $50.0 \%$ cases $^{10}$. This insensitivity for small and moderate decreases in GFR in creatinine blind area gives a false impression and lead to late detection of kidney damage. So it is less reliable and less accurate. Cystatin $\mathrm{C}$ is an alternative marker to assess renal function, which is better than creatinine in regard of creatinine blind area $^{11}$. It is not influenced by extra-renal manifestations like creatinine and can detect AKI one to two days prior to increase serum creatinine.

Early detection and intervention can prevent further progression of renal injury and hence decrease complication, morbidity and mortality ${ }^{7}$. There was no such study so far in this regard in Bangladesh. Therefore, this study was carried out in the Department of Pediatric Nephrology, Bangabandhu Sheikh Mujib Medical University to assess serum cystatin $\mathrm{C}$ level in patients who were at risk of AKI. The purpose of the present study was to validate the serum cystatin for the detection of acute kidney injury in children.

\section{Methodology}

This cross-sectional study was conducted in the Department of Paediatric Nephrology with the collaboration of Paediatric Gastroenterology, Paediatric Neurology, Paediatric Neonatology and Microbiology and Immunology at Bangabandhu Sheikh Mujib University, Dhaka, Bangladesh from May 2018 to July 2019 for a period of one year. Patients with the age group of 1 month to 17 years, who were at risk of AKI, and admitted in the inpatient department of Pediatrics and allied at Bangabandhu Sheikh Mujib University, Dhaka, Bangladesh during this study period in both sexes were selected as study population. Patients with nephrotic syndrome at risk of AKI due to hypovolemia or shock, sepsis, use of nephrotoxic drugs for at least 5 days or patients other than nephrotic syndrome with hypovolemia, use of nephrotoxic drugs for at least 5 days and patients with obstructive uropathy and congenital heart disease needed to use radiocontrast agent were included in this study. Patient already diagnosed as AKI, preterm or patients with hypothyroidism and malignancy were excluded from this study. Patients were selected by purposive sampling technique. For exclusion of malignancy and thyroid disorder proper history taking, examination, related investigations $\left(\mathrm{FT}_{4}, \mathrm{TSH}\right)$ and imaging were done. Serum cystatin $\mathrm{C}$ were measured at 0 (baseline) and $48 \mathrm{~h}$ respectively for all patients. $0 \mathrm{~h}$ (baseline) was considered when patients presented with hypovolemia / shock due to diarrhoea and / or vomiting, features of sepsis, $24 \mathrm{~h}$ after taking nephrotoxic drugs and $4 \mathrm{~h}$ after exposure of radiocontrast agent. Sepsis was diagnosed as per protocol. Blood samples were collected on 3 and 5 day with aseptic precaution in Vacutainer test tube without any preservative and labelled with patient's name, ID number, date of collection, name of ward. Collected blood were sent for following investigations to Microbiology and Immunology Laboratory of BSMMU for serum cystatin C by particle enhanced nephelometric immunoassay (PENIA) for the quantitative measurement. Biochemistry Laboratory of BSMMU for serum creatinine by Kinetic Alkaline Picrate Method- Jaffe reaction, serum $\mathrm{FT}_{4}$ and TSH. Data was collected with appropriate questionnaire containing proper history, clinical examination and findings of laboratory reports of enrolled patients who fulfilled the inclusion criteria after taking informed written consent. All the cases were numbered chronologically. The data were collected and edited manually. The entered data were checked, verified and analyzed by appropriate computer software. Statistical analysis was performed by using SPSS for 
windows version 22 . The data were presented in tubular or diagrammatical form. All qualitative data were expressed as frequency and percentages. All quantitative data were expressed as mean $\pm \mathrm{SD}$. An analysis plan was developed keeping in view with the objectives of the study. Unpaired t-test and paired $\mathrm{t}$-test were done whenever required. For all statistical test $\mathrm{p}<0.05$ was considered statistically significant. Prior to the commencement of this study, the thesis protocol was placed and approved by the Institutional Review Board of BSMMU, Dhaka. For recruitment of study population permission was taken from Pediatrics and allied department. Every ethical issue was discussed with the patient's parents regarding the study. Parents were clearly informed about the nature and purpose of the study, procedures followed, risk associated with it and benefits from the study in easily understandable local language.

\section{Result}

A total number of 52 patients, who fulfilled the inclusion criteria were enrolled in this study.

Table 1: Age Distribution of the Study Subjects in Older Age Group (n=42)

\begin{tabular}{|l|c|c|}
\hline Group & $\begin{array}{c}\text { Age } \\
(\text { Mean } \pm \text { SD })\end{array}$ & P value \\
\hline AKI & $11.3 \pm 3.7$ & \multirow{2}{*}{0.007} \\
\hline Non AKI & $7.1 \pm 4.9$ & \\
\hline
\end{tabular}

Unpaired $t$ test was done

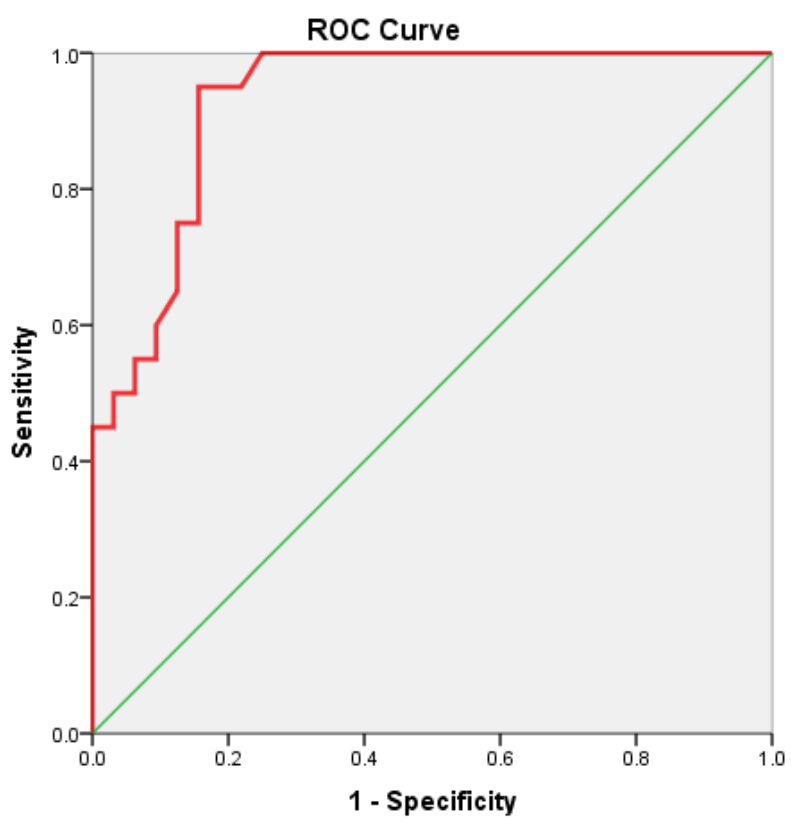

Figure I: ROC of serum cystatin $C$ at $48 \mathrm{~h}$ in predicting AKI
Among them 42 cases were in older age group and 10 were in neonatal age group. Twenty patients (38.0\%) developed acute kidney injury. The mean age in older age group of AKI was $11.3 \pm 3.7$ years and non-AKI group was $7.1 \pm 4.9$ years. The difference between the AKI and non-AKI was statistically significant $(\mathrm{p}=0.007)$ (Table 1$)$.

Table 2: Area Under the Curve (AUC) of Serum cystatin $\mathrm{C}$

\begin{tabular}{|l|c|}
\hline Parameter & Value \\
\hline AUC Value & 0.930 \\
\hline SE & 0.033 \\
\hline P value & 0.000 \\
\hline 95\% CI & 0.864 to 0.995 \\
\hline
\end{tabular}

Figure I showed the ability of serum cystatin $\mathrm{C}$ in predicting AKI at $48 \mathrm{~h}$. Here the AUC was 0.93 with $95 \%$ CI (0.864 - 0.995).

According to Youden index the best cut off value of serum cystatin $\mathrm{C}$ at $48 \mathrm{~h}$ was $1.35 \mathrm{mg} / \mathrm{L}$ in predicting AKI with sensitivity 0.95 (95\%) and specificity 0.84 (84\%) (Table 3).

Table 3: Youden index of serum cystatin $C$ at 48 $h$ in predicting AKI

\begin{tabular}{|c|c|c|c|c|}
\hline 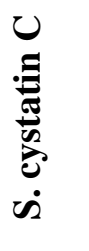 & 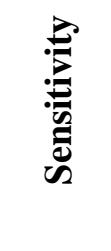 & 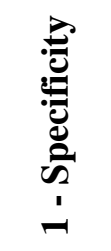 & 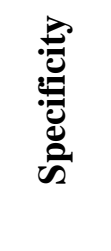 & 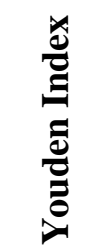 \\
\hline 1.06 & 1.000 & 0.375 & 0.625 & 0.625 \\
\hline 1.13 & 1.000 & 0.344 & 0.656 & 0.656 \\
\hline 1.16 & 1.000 & 0.313 & 0.688 & 0.688 \\
\hline 1.21 & 1.000 & 0.250 & 0.750 & 0.750 \\
\hline 1.27 & 0.950 & 0.219 & 0.781 & 0.731 \\
\hline 1.30 & 0.950 & 0.188 & 0.813 & 0.763 \\
\hline 1.35 & 0.950 & 0.156 & 0.844 & 0.794 \\
\hline 1.38 & 0.900 & 0.156 & 0.844 & 0.744 \\
\hline 1.39 & 0.850 & 0.156 & 0.844 & 0.694 \\
\hline 1.45 & 0.800 & 0.156 & 0.844 & 0.644 \\
\hline
\end{tabular}

At cut-off value $1.35 \mathrm{mg} / \mathrm{L}$ serum cystatin $\mathrm{C}$ had sensitivity of $95 \%$ (95\% CI 0.779-0.997) with specificity $84 \%$ (95\% CI $0.737-0.873$ ), PPV $79 \%$ (95\% CI 0.649-0.831), NPV 96\% (95\% CI 0.8420.998 ), accuracy $88.7 \%$ (95\% CI $0.753-0.921$ ), positive likelihood ratio 6.08 and negative likelihood ratio 0.06 (95\% CI 2.96-7.87 and 0.003-0.300 respectively) (Table 4$)$. 
Table 4: Diagnostic Efficiency Values for serum cystatin $C$ in predicting AKI at 48 hours

\begin{tabular}{|l|c|c|}
\hline Parameters & Value & $\mathbf{9 5 \%}$ CI \\
\hline Sensitivity & $95.0 \%$ & 77.9 to 099.7 \\
\hline Specificity & $84.4 \%$ & 73.7 to 87.3 \\
\hline PPV & $79.2 \%$ & 64.9 to 83.1 \\
\hline NPV & $96.4 \%$ & 84.2 to 99.8 \\
\hline Accuracy & $88.5 \%$ & 75.3 to 92.1 \\
\hline Positive LR & 6.08 & 2.96 to 7.87 \\
\hline Negative LR & 0.06 & 0.003 to 0.300 \\
\hline
\end{tabular}

\section{Discussion}

This was a prospective analytical study done on critically and non-critically ill admitted patients in all age group, who were at risk of AKI. The aim was to see the predictive value of cystatin $\mathrm{C}$ for earlier diagnosis of acute kidney injury in children. An incidence of AKI of $38.0 \%$ had been demonstrated in patients between 4 days to 17 years of age admitted to BSMMU in different departments during study period. Almost similar finding was found by Sutherland et $\mathrm{al}^{12}$ where incidence of AKI was of $39 \%$ in children. A total 52 children were analyzed in this study. Forty two patients were in older age group and ten patients in neonatal age group. The mean age in older age group of AKI was $11.3 \pm 3.7$ years, is similar to Haque et $\mathrm{al}^{13}$. They found the incidence was higher in older patients.

Since the incidence of AKI is quite high, for prevention and better outcome cystatin $\mathrm{C}$ was chosen as a new early biomarker to predict AKI. In this study it was found that the AUC was 0.93 for ability to detect AKI. With cut-off value of $1.35 \mathrm{mg} / \mathrm{L}$ the sensitivity, specificity, PPV, NPV, accuracy, positive likelihood ratio and negative likelihood ratio were $95.0 \%, 84.0 \%, 79.0 \%, 96.0 \%, 88.7 \%, 6.08$ and 0.06 respectively. Though this finding showed no similarity with previous study, Ataei et $\mathrm{al}^{14}$ found cystatin C had higher AUC, sensitivity, specificity, accuracy, positive likelihood ratio than serum creatinine in predicting AKI within $48 \mathrm{~h}$ in critically ill children. Lagos-ArevaloBSc et $\mathrm{al}^{15}$ reported that the best cut-off for cystatin C AKI was $1.3 \mathrm{mg} / \mathrm{L}$ using KDIGO criteria, favoring high specificity. Bagheri et $\mathrm{al}^{6}$ found cystatin $\mathrm{C}$ had greater AUC (0.96) to predict AKI on third day, is almost similar with present study. In another study El-Gamasy ${ }^{7}$ it has been found that with the cut-off value $\geq 0.6 \mathrm{mg} / \mathrm{L}$ cystatin C had higher AUC, sensitivity, specificity, accuracy than serum creatinine on third day of incubation in full term neonates who fulfilled the criteria according to KDIGO. Another study by Hamed et $\mathrm{al}^{1}$ found that cystatin $\mathrm{C}$ was a poor biomarker for diagnosing AKI in critically ill children.

Ozdemir et $\mathrm{al}^{16}$ found in a pediatric study that cystatin $\mathrm{C}$ and creatinine significantly increased substantially at $4 \mathrm{~h}, 24 \mathrm{~h}$ and $48 \mathrm{~h}$ after cardiac angiography. The present study revealed similar finding. Additional finding was two patients developed raised serum cystatin $C$ level 1 day prior to creatinine. Lau et $\mathrm{al}^{17}$ reported rise from baseline expressed as fold-wise increase two days before $\mathrm{SCr}$ AKI (Day-2) after getting aminoglycoside. There was 1.5 fold rise of median value of cystatin $C$. The present study also demonstrated similar pattern of rise of cystatin $\mathrm{C}$ and presumable use of it as early marker. In this study, we found only $30.0 \%$ patients with AKI were detected at 48 hours by creatinine and rest of them were detected 1 to 2 days later, whereas cystatin $\mathrm{C}$ detected AKI at 48 hours This reflected that cystatin $\mathrm{C}$ increased in serum rapidly and earlier than creatinine.

In this study explored that no parameters like age, sex, height, weight, BMI and risk factors of AKI had significant effect on cystatin C. Bokenkamp et $\mathrm{al}^{2}$ found serum cystatin $\mathrm{C}$ reflects renal function independent of age, gender, height and body mass composition. This finding is similar to the finding of present study. Schwartz et $a^{18}$ found that the production apparently independent of inflammatory conditions, muscle mass, sex, age (after 1 month). Another study by Krause et al ${ }^{19}$ reported that older age, male gender, greater weight, greater height and higher C- reactive protein levels were independently associated with higher serum cystatin C levels. Martensson et $\mathrm{al}^{20}$ found inflammatory response induced by sepsis had no impact on the levels on cystatin $\mathrm{C}$ in plasma. The present study showed similar finding.

\section{Conclusion}

In conclusion the serum cystatin $\mathrm{C}$ can be considered an effective and early marker for detection of acute kidney injury in risk group of children. The sensitivity and specificity are also very high which indicates that it can detect AKI very accurately. The area under the curve is also significantly high. Therefore, serum cystatin $\mathrm{C}$ should be measured to detect the acute kidney injury among children.

\section{References}

1. Hamed HM, El-Sherbini SA, Barakat NA, Farid TM, Rasheed EA. Serum cystatin C is a poor biomarker for diagnosing acute kidney injury in critically-ill children. Indian Journal of Critical Care Medicine 2013;17(2):92-98 
2. Bokenkamp A, Van Wijk JA, Lentze MJ, Stoffel-Wagner B. Effect of corticosteroid therapy on serum cystatin $C$ and $\beta 2$ microglobulin concentrations. Clinical chemistry. 2002;48(7):1123-5.

3. Lujambio I, Sottolano M, Luzardo L, Robaina S, Krul N, et al. Estimation of glomerular filtration rate based on serum cystatin $\mathrm{C}$ versus creatinine in a Uruguayan population. International journal of nephrology. 2014;2014: 1-9.

4. Zaffanello M, Franchini M, Fanos V. Is serum Cystatin-C a suitable marker of renal function in children? Annals of Clinical \& Laboratory Science. 2007;37(3):233-40.

5. Lau L, Al-Ismaili Z, Harel-Sterling M, Pizzi M, Caldwell JS, Piccioni $M$, et al. Serum cystatin $C$ for acute kidney injury evaluation in children treated with aminoglycosides. Pediatric Nephrology. 2017;32(1):163-71

6. Bagheri S, Esmaeeli M, Ravanshad Y, Azarfar A, Foroutan A, Ravanshad S, Mehrad-Majd H, Alizadeh A. Cystatin C as a biomarker of acute kidney injury in a group of critically ill children in a pediatric intensive care unit. Journal of Renal Injury Prevention. 2018;7(4):259-63.

7. El-Gamasy MA. Early predictors of Acute Kidney Injury (AKI) in a sample of Egyptian full term Neonates. Med Clin Rev. 2017;3(3):12.

8. Nakhjavan-Shahraki B, Yousefifard M, Ataei N, Baikpour M, Ataei F, Bazargani B, Abbasi A, Ghelichkhani P, Javidilarijani F, Hosseini M. Accuracy of cystatin C in prediction of acute kidney injury in children; serum or urine levels: which one works better? A systematic review and metaanalysis. BMC nephrology. 2017;18(1):120.

9. Prasad BS, Kumar M, Dabas A, Mishra K. Profile of acute kidney injury in hospitalized children with idiopathic nephrotic syndrome. Indian pediatrics. 2019;56(2):119-22.

10. Safdar OY. Serum Cystatin C Is A Useful Biomarker but Not Superior to Serum Creatinine Assessment for The Diagnosis of Acute Kidney Injury in Septic Children: A Prospective Cohort Study. Journal of Translational Science 2016;2(1):74-78

11. Sawada M, Ueda K, Yoshizaki K, Tokumasu S, Kubota M.
Serum Cystatin C as a Useful Marker for Evaluation of Renal Function at Birth: a Pilot Study. J Clin Exp Nephrol. 2019;4(1):01

12. Sutherland SM, Ji J, Sheikhi FH, Widen E, Tian L, Alexander SR, Ling XB. AKI in hospitalized children: epidemiology and clinical associations in a national cohort. Clinical journal of the American Society of Nephrology. 2013;8(10):1661-9

13. Huque SS, Begum A, Rahman MH, Uddin GM, Roy RR, Mannan MA, et al. Spectrum of Hospital Acquired Acute Kidney Injury in Critically ill Children in a Tertiary Level Hospital. Journal of Pediatric Nephrology. 2017;5(2)

14. Ataei N, Bazargani B, Ameli S, Madani A, Javadilarijani F, Moghtaderi M, et al., Early detection of acute kidney injury by serum cystatin $\mathrm{C}$ in critically ill children. Pediatric Nephrology. 2014;29(1):133-8

15. Lagos-Arevalo P, Palijan A, Vertullo L, Devarajan P, Bennett MR, Sabbisetti V, et al. Cystatin $C$ in acute kidney injury diagnosis: early biomarker or alternative to serum creatinine? Pediatric Nephrology. 2015;30(4):665-76

16. Özdemir O, Oğuz AD, Eren A, Şanli C, Söylemezoğlu HO, Çayci AB. Cystatin $\mathrm{C}$ as biomarker of contrast-induced nephropathy in pediatric cardiac angiography. Turkish journal of medical sciences. 2014;44(2):178-85

17. Lau L, Al-Ismaili Z, Harel-Sterling M, Pizzi M, Caldwell JS, Piccioni $M$, et al. Serum cystatin $C$ for acute kidney injury evaluation in children treated with aminoglycosides. Pediatric Nephrology. 2017;32(1):163-71

18. Schwartz GJ, Work DF. Measurement and estimation of GFR in children and adolescents. Clinical Journal of the American Society of Nephrology. 2009;4(11):1832-43

19. Krause I, Cleper R, Eisenstein B, Davidovits M. Acute renal failure, associated with non-steroidal anti-inflammatory drugs in healthy children. Pediatric Nephrology. 2005;20(9):1295-8

20. Mårtensson J, Martling CR, Oldner A, Bell M. Impact of sepsis on levels of plasma cystatin $\mathrm{C}$ in AKI and non-AKI patients. Nephrology Dialysis Transplantation. 2012;27(2):57681 